\title{
ADMINISTRAÇÃO PÚBLICA E O PAPEL DAS AGÊNCIAS REGULADORAS
}

\section{ARTIGO ORIGINAL}

SOUZA NETO, Antônio Teotônio De ${ }^{1}$

SOUZA NETO, Antônio Teotônio De. Administração Pública e o papel das Agências Reguladoras. Revista Científica Multidisciplinar Núcleo do Conhecimento. Ano 05, Ed. 10, Vol. 21, pp. 119-132. Outubro de 2020. ISSN: 2448-0959, Link de acesso: https://www.nucleodoconhecimento.com.br/administracao/agencias-

\section{reguladoras}

\section{RESUMO}

O trabalho intitulado Administração Pública e o Papel das Agências Reguladoras visa demonstrar que estas autarquias de regime especial surgiram após a descentralização de serviços públicos, que possibilitaram a dissolução de alguns monopólios estatais e os ofícios passaram a ser executados pela iniciativa privada, como são atividades essenciais ao bem comum, foram criadas as agências reguladoras com a finalidade de editar normas para condução destes mercados. Dessa forma buscou-se elucidar o questionamento: que aparato dispõe as agências reguladoras para proporcionar ao mercado regulado serviços e bens de qualidade? Objetivou-se pesquisar quais os mecanismos que as Agências Reguladoras utilizam para promover a estabilidade do mercado e o bem-estar dos agentes envolvidos, como também a expectativa e proposição pelos princípios e métodos científicos e os princípios básicos da administração pública. Utilizou-se a metodologia com enfoque qualitativo e o estudo descritivo, foi uma pesquisa bibliográfica, os instrumentos de

\footnotetext{
${ }^{1}$ Doutor em Administração pela Universidade Nacional de Rosário - UNR - Argentina; Especialista em Recursos em Minerais/Economista da Agência Nacional de Mineração; Especialista em Gestão e Legislação Tributária; Bacharel em Ciências Econômicas.
} 
coleta de dados foram: livros, revistas, artigos e a legislação correlata. A investigação demonstrou que a administração pública procurou alcançar eficiência, eficácia e efetividade à medida que foi se modernizando, que através da regulação procura-se harmonizar e manter os direitos dos usuários, governo e das empresas, que a autonomia dessas autarquias de regime especial permite que as decisões sejam pautadas em bases técnicas com a finalidade de manter o equilíbrio do mercado com preço justo e oferta de bens e serviços de qualidade.

Palavras-chave: Autonomia, ciência, princípios.

\section{INTRODUÇÃO}

O presente trabalho aborda a expectativa pelos princípios e métodos científicos na administração pública, onde os cientistas sociais e autores de administração pública procuraram efetuar estudos com um conjunto de regras para desenvolver experimentos objetivando buscar novos conceitos de gestão pública.

Demonstra que ao longo do tempo intensificaram-se os estudos com a administração pública perpetrando uma exposição mais metódica e científica, havendo assim um esforço para proporcionar guias de ações em vistas de maior eficiência.

Explana que a administração pública é norteada por princípios para se chegar ao resultado pretendido, só sendo permitido fazer o que a lei autoriza, diferenciando-se do particular que é lícito praticar tudo que a lei não proíbe, desta forma pautaram-se os princípios básicos de diretrizes das entidades governamentais: legalidade, impessoalidade, moralidade, publicidade e eficiência.

Descreve ainda, a necessidade de criação das agências reguladoras diante do advento da nova gestão pública, onde ocorreu à descentralização de serviços do setor público para iniciativa privada, demonstra a importância da autonomia para que essas autarquias de regime especial possam tomar decisões pautadas em bases técnicas, procura também, apresentar como as agências reguladoras devem conciliar os 
interesses do consumidor, fornecedor, governo e produtor harmonizando preço e qualidade.

\section{CIÊNCIA E ADMINISTRAÇÃO PÚBLICA}

A administração pública é uma área do conhecimento onde perpetrou a expectativa pelos princípios e métodos científicos, os autores de administração pública e outros cientistas sociais perquiriam realizar estudos científicos de gestão pública, segundo Denhardt (2012), frequentemente abordou-se desde as primeiras obras literárias sobre administração pública o termo ciência ou princípios, estes também no mesmo sentido de ciência, porém de forma obscura e subjetiva.

O livro "Administrative behavior (1957) de Hebert A. Simon", foi precursor de um modelo formulado com cuidados epistemológicos fundamentados, antes não havia os procedimentos científicos próprio do trabalho científico e a exigência pela abordagem nos preceitos do método científico.

De acordo com Denhardt (2012), diversos autores contribuíram para a abordagem cientifica de Simon, o livro Principles of public administration (1927), de autoria de Willoughby expõe em seu prefácio que pode haver contradição em afirmar que a administração pode ser analisada como ciência. Independentemente de a contradição ter ou não fundamento, verifica-se predicados de que em administração há princípios fundamentais que podem ser usados em outros campos do conhecimento, similares aos que fundamentam os outros ramos científicos, portanto esses princípios devem ser seguidos com o emprego rigoroso do método e da investigação cientifica.

No sentido de tornar uma ciência social plausível, segundo Denhardt (2012), Leonardo D. White em seu trabalho intitulado The meaning of principles in public administration (1936), argumenta que o termo "princípio" já não seja mais apropriado para desenvolver pesquisa científica. Desse modo no pensamento de White, deve-se restringir o termo para que descreva uma hipótese ou proposição testada por experimento ou observação, sugerida como orientação da ação ou como forma de 
entendimento. Diante dessa proposição ocorreu uma maior disposição no estudo científico da administração pública.

Em 1940 de acordo com Denhardt (2012), no ensaio com o título de "An Approach to a Science of administration", Edwin $\mathrm{O}$. Stene remeteu o estudo de administração pública para uma exposição mais metódica e científica, havendo assim, um esforço de proporcionar guias de ações em vistas de maior eficiência. Entretanto, Waldo proferiu que a ciência política estaria distanciando-se da importância antes atribuída à filosofia moral e a economia política, mergulhando no que seria a verdadeira ciência da política, desse modo, quando a nova ciência política se uniu com a ideologia progressiva da eficiência administrativa, as consequências tornaram-se um tanto quanto inquietantes, Waldo mencionou que ocorreu um afastamento da crença de que o problema do bom governo também seria dos homens morais, porem iriam convergir para o posicionamento antagônico, ou seja irrelevância da moralidade.

Segundo Denhardt (2012), a eficiência administrativa ambicionada pelos autores precursores não repercutiu da forma esperada nas instituições democráticas, limitando-as e não as libertando da responsabilidade moral.

Em seu livro "Administrative behavior", Simon expõe que a função do cientista é pesquisar hipóteses baseadas em fatos, tendo como aparato o exame da evidência do comportamento ou conjecturas logicamente inferidas dessas experiências, Simon menciona, de acordo Denhardt.

A objetividade do cientista é de extrema importância e, por essa razão, ele deve ter o cuidado de estabelecer bases factuais para quaisquer conclusões passíveis de serem tiradas. Para impedir que a subjetividade interfira no processo de pesquisa, o cientista deve purgar suas teorias de toda e qualquer intimidade com os valores humanos subjetivos (DENHARDT, 2012, p. 106).

Com uma visão positivista sobre o desempenho das organizações, o pensamento de Simon é que são positivos os procedimentos que acrescentam novas formas para se alcançar as metas em uma organização, e negativos os processos que não induzem 
o aumento dessa capacidade. Nessa concepção a eficiência na administração pública é algo a ser ambicionado pelas organizações governamentais.

Em um mundo globalizado onde fenômenos econômicos e sociais acontecem em uma velocidade impressionante estimulado pela tecnologia da informação e pelos sistemas de dados, se faz necessário que a Administração Pública se modernize para atender as demandas dinâmicas da sociedade, permitindo a avaliação da gestão implementada e do seu desempenho.

\subsection{PRINCÍPIOS BÁSICOS DA ADMINISTRAÇÃO PÚBLICA}

A administração pública é norteada por princípios para se chegar ao resultado pretendido, encontra-se no artigo 37, caput, da Constituição federal os princípios básicos de diretrizes das entidades governamentais: legalidade, impessoalidade, moralidade, publicidade e eficiência.

O princípio da legalidade- é imperativo para os ditames dos Países regidos pelo Estado de direito, ao exprimir que a administração pública em seus atos deve pautar pelo que está fixado nas normas legais, importante salientar que esse princípio inicialmente resultou das ideias contrarias ao período absolutista, de acordo com Medauar.

Tornaram-se clássicos quatro significados arrolados pelo francês Eisenmann: a) a Administração pode realizar todos os atos e medidas que não sejam contrários à lei; b) a Administração só pode editar atos ou medidas que uma norma autoriza; c) somente são permitidos atos cujo conteúdo seja conforme a um esquema abstrato fixado por norma legislativa; d) a Administração só pode realizar atos ou medidas que a lei ordena fazer (MEDAUAR, 2007, p.122).

A Administração Pública encontra as diretrizes na previsão legal não podendo se distanciar, seus agentes devem agir conforme o que está estabelecido na lei, sendo esta proclamada pelos representantes do povo, pois todo poder emana do povo.

Segundo Bittencourt (2007), A administração pública não possui poder de instituir aos cidadãos obrigações ou direitos por meio de ato administrativo, ninguém é obrigado a 
fazer ou deixar de fazer alguma coisa senão em virtude de lei, apenas a lei aprovada pelo legislativo tem o condão de alterar o ordenamento jurídico.

Princípio da Impessoalidade - veda a Administração Pública de agir em prol de determinada pessoa ou grupo, devendo sempre zelar pelo interesse público, para Hely Lopes Meireles (1998), o princípio da impessoalidade representa o próprio princípio da finalidade pública ao determinar à atuação do agente a finalidade pública, devendose praticar atos de forma impessoal por determinação legal. Para Bittencourt (2007), os atos administrativos são atribuídos à pessoa jurídica e não ao servidor público que o praticou.

Princípio da Moralidade - direciona o agente público a atuar em consonância com padrões éticos e morais, aqueles administradores que agirem com atos de improbidade responderam civil e criminalmente, de acordo com o artigo 37, § $4^{\circ}$ da Constituição Federal (1988), os atos de improbidade administrativa importarão a suspensão dos direitos políticos, a perda da função pública, a indisponibilidade dos bens e o ressarcimento ao erário, na forma e gradação previstas em lei, sem prejuízo da ação penal cabível.

Princípio da Publicidade - informa que a Administração Pública deve agir com transparência, de modo que a sociedade possa exercer o controle e ter visibilidade das ações no trato da coisa pública, sendo indispensável para manutenção da democracia, para Medauar (2007), O princípio da publicidade deve ser respeitado em todas as esferas da administração pública.

Princípio da Eficiência - com a reforma administrativa da Constituição Federal através Emenda Constitucional número 19/98, foi introduzido o princípio da eficiência que passou a fazer parte dos princípios básicos da administração pública, desse modo o Estado brasileiro mudou a visão de gestão pública apenas burocrática, passando a buscar resultados. Segundo Bittencourt.

A explicitação da eficiência passa a incrementar o exercício da autotutela e a fiscalização social da atividade administrativa. Assim, exige-se a apresentação de resultados positivos para o serviço público e satisfatório 
atendimento das necessidades do administrado não apenas na conduta do servidor público, mas também de toda administração pública (BITTENCOURT, 2007, p. 34).

O princípio da eficiência busca que o serviço público aja com celeridade, esmero e rendimento, sempre perseguindo o máximo que satisfaça a população com o mínimo de custo, no entendimento de Medauar (2007), o princípio da eficiência estabelece que administração pública em suas ações deve atuar com agilidade e perfeição na busca de resultados que atendam o bem-estar da população.

O conceito de administração pública se torna complexo devido à própria expressão e distintos campos utilizados para consecução da atividade administrativa, no entanto para Matias-Pereira.

A Administração pública, no sentido amplo, designa o conjunto de serviços e entidades incumbidos de concretizar as atividades administrativas, ou seja, da execução das decisões políticas e legislativas. Assim, a Administração pública tem como propósito a gestão de bens e interesses qualificados da comunidade no âmbito dos três níveis de governo: federal, estadual e municipal, segundo preceitos de Direito e da Moral, visando o bem comum (MATIAS-PEREIRA, 2008, p.60).

Para Di Pietro (2004), a administração pública compreende um significado subjetivo e outro objetivo. Em sentido subjetivo, é o conjunto de organizações públicas que a lei outorgou competência para exercera função administrativa, de modo que, a função administrativa é executada pelas entidades do Poder Executivo, entretanto, o regime constitucional não atribui à separação irrestrita de atividades e sim das especializações das funções, os Poderes Judiciário e Legislativo do Estado também a exercem para executar suas finalidades que são suas competências por excelência. Em sentido objetivo a administração pública tem como propósito a gestão de bens e interesses qualificados da comunidade, satisfaz à função administrativa.

De acordo com Di Pietro (2004), A administração pública em sentido objetivo compreende as atribuições executadas pelo conjunto de órgãos, pessoas jurídicas e servidores públicos encarregados de suprir os anseios da população buscando 
proporcionar o bem-estar social, a função administrativa é competência dos órgãos do poder executivo, porém os outros poderes também a exerce.

A conceituada autora menciona ainda que em sentido material ou objetivo, (DI PIETRO, 2004, p.61), "Administração Pública pode ser definida como a atividade concreta e imediata que o Estado desenvolve sob regime jurídico de direito público, para a consecução dos interesses coletivos".

O estado tem como finalidade proporcionar o bem comum para população, enquanto espaço natural de desenvolvimento político necessita dispor de aparato administrativo para consecução, ajustamento e ordenamento orgânico, de forma a assegurar aos cidadãos o bem-estar, a segurança e a justiça.

\subsection{O PAPEL DAS AGÊNCIAS REGULADORAS}

Com a finalidade de proporcionar uma gestão pública que atenda os anseios da população, foram introduzidos na administração pública procedimentos para alcançar eficiência, eficácia e efetividade, ainda que no passado recente no setor público a sobrevivência do gestor não estivesse associada ao desempenho da instituição, na nova gestão pública os resultados passam a ser uma forma de controle.

Com o advento da nova gestão pública surge a descentralização de serviços, possibilitando que alguns monopólios estatais sejam quebrados e os ofícios passem a ser executados pela iniciativa privada como ocorreu no setor de energia e telecomunicações, porém, como esses serviços são essenciais ao bem comum, foram criadas as agências reguladoras, com a finalidade de editar normas de condução nestes mercados. Para Pinheiro:

A criação das agências reguladoras constitui mecanismo delimitador das fronteiras dos serviços públicos para: fixar normas para a definição de tarifas; fiscalizar o cumprimento dos atos regulatórios; estimular a competência dos prestadores de serviços; e mediar os interesses desses agentes e dos usuários e consumidores, abrindo campo a novos investimentos privados, nacionais e estrangeiros. Nesse afã, as agências devem ser autônomas frente aos governos e ao mercado, em função dos interesses públicos envolvidos. (PINHEIRO, 2009, p. 42). 
As agências reguladoras são pessoas jurídicas de direito público, classificadas como autarquias de regime especial. Tal natureza é essencial para que desempenhem efetivamente seu papel, que consiste em intervir no domínio econômico e fiscalizar a prestação de serviços públicos, ou seja, deveres específicos do Estado.

No Brasil existem onze Agências Reguladoras Federais, sendo oito de infraestrutura ANATEL, ANAC, ANEEL, ANP, ANTAQ, ANTT, ANA e ANM, e três da área social ANS, ANVISA e ANCINE, muito se discutiu sobre o modelo institucional das agências reguladoras desde a instalação da ANATEL, primeira autarquia reguladora brasileira.

Alguns autores afirmavam que as agências da área social não necessitariam de autonomia e desvinculação política em relação ao governo, entretanto, com o advento da Lei $n^{0}$ 13.848/2019, o formato dessas autarquias especiais foi equiparado pelos ditames legais.

O modelo das agências reguladoras, sejam elas de infraestrutura ou da área social, conforme disposição legal, é de não subordinação a outros órgãos, autonomia funcional, decisória, administrativa e financeira e pela investidura a termo de seus dirigentes e estabilidade durante os mandatos.

A autonomia é a principal característica das agências reguladoras, permite tomadas de decisões em bases técnicas, assim suas ações possibilitam a estabilidade do mercado e o bem-estar dos agentes envolvidos, ou seja, o equilíbrio dos direitos dos usuários dos serviços, governo e empresa executora do serviço ou bem. A autonomia verifica-se por meio de um conjunto de independências: Financeira, Estrutural, Funcional e Decisória. Para Helena Kerr do Amaral na apresentação do livro Desafios da regulação no Brasil,

No intuito de contribuir para o aprimoramento do sistema regulatório brasileiro e para a melhoria da qualidade da regulação, são necessárias intervenções estratégicas de transformação da gestão pública voltadas ao alcance da eficiência, eficácia e efetividade da ação governamental (BRASIL, 2009, p.7). 
A independência financeira é possível graças à fonte de receita própria geralmente do mercado regulado; a independência estrutural diz respeito a um quadro próprio e especializado; a independência funcional se concretiza pelo mandato fixo dos seus dirigentes que permanecem no cargo por um período sem interferência política para destituí-los; a independência decisória incide na competência da agência em poder resistir a pressões dos grupos de interesses do setor regulado.

As agências reguladoras exercem a competência do poder concedente, estabelecendo o regramento de transferência do serviço estatal para a iniciativa privada, desempenham papel fundamental nos setores econômicos, regulando, fiscalizando, mediando, e arbitrando os conflitos dentro do mercado que regula.

$\mathrm{Na}$ busca de proporcionar o bem-estar à sociedade as agências reguladoras devem conciliar os interesses do consumidor, fornecedor e produtor, harmonizando preço e qualidade, de forma que haja no mercado em que atua viabilidade econômica para todos os envolvidos.

Para melhorar a qualidade dos serviços fornecidos pelas empresas do setor regulado, a agência reguladora exerce a fiscalização da atividade econômica, podendo realizar vistorias, notificar, autuar infratores, adotar medidas acautelatórias como de interdição e paralisação, impor as sanções cabíveis, firmar termo de ajustamento de conduta, constituir e cobrar os créditos delas decorrentes.

É função primordial das agências reguladoras promover mediante fiscalização, que os serviços sejam prestados adequadamente, fazendo com que as cláusulas estabelecidas nos contratos sejam cumpridas integralmente ensejando sempre a promoção da competitividade do mercado.

Objetivando harmonizar a atividade econômica do mercado em que atua, a agência reguladora deve fomentar a concorrência entre os agentes econômicos, monitorar e acompanhar as práticas de mercado do setor e cooperar com o Conselho Administrativo de Defesa Econômica - CADE. 
As agências reguladoras nasceram com a incumbência de fiscalizar a prestação de serviços públicos e bens concedidos pelo Estado a iniciativa privada, cabendo também controlar a qualidade da prestação destes serviços, estabelecendo regras e fiscalizando as suas execuções.

Segundo Roque (2004), uma entidade reguladora dispõe de capacidade de conciliação e arbitramento dos conflitos entre os agentes envolvidos mantendo harmonia no setor regulado, pois detém a competência para fiscalizar, podendo efetuar inspeções, notificar, autuar infratores, fazer informativos e orientações de natureza prudencial, adotar medidas acautelatórias como de interdição e paralisação, cooperar e manter comunicação com outros órgãos similares da administração pública.

Em síntese, o papel das Agências Reguladoras Federais no Brasil é de outorga, fiscalização, regulamentação, arbitramento do mercado e, controle de bens e serviços no setor em que regulam, entretanto, cada uma delas tem atribuições próprias, de modo que essas autarquias federais atuam da seguinte forma:

- Agência Nacional de Vigilância Sanitária é vinculada ao Ministério da Saúde atua resguardando e promovendo a saúde da população, com ações visando impedir eventual ameaça em consequência da produção e do uso de produtos e serviços submetidos à vigilância sanitária;

- Agência Nacional de Águas é vinculada ao Ministério do Desenvolvimento Regional realiza ações sustentáveis objetivando proporcionar segurança hídrica no Brasil;

- Agência Nacional de Aviação Civil é vinculada ao Ministério da Infraestrutura suas atividades são voltadas para promover a segurança e a excelência da aviação civil.

- Agência Nacional do Cinema é vinculada ao Ministério do Turismo trabalha para alavancar o desempenho do setor audiovisual em benefício da sociedade brasileira;

- Agência Nacional de Telecomunicações é vinculada ao Ministério da Ciência, Tecnologia, Inovações e Comunicações tem o propósito de ajustar o setor de 
telecomunicações para colaborar com o desenvolvimento do Brasil através da regulação;

- Agência Nacional de Energia Elétrica é vinculada ao Ministério de Minas e Energia realiza ações para desenvolver o mercado de energia elétrica visando proporcionar o equilíbrio entre os agentes e em benefício da sociedade;

- Agência Nacional de Mineração é vinculada ao Ministério de Minas e Energia tem a incumbência de conduzir o setor mineral brasileiro através da regulação, suas diretrizes são sustentabilidade econômica, desenvolvimento social e ambiental;

- Agência Nacional do Petróleo, Gás Natural e Biocombustíveis é vinculada ao Ministério de Minas e Energia regula as atividades econômicas das indústrias de petróleo, do gás natural, seus derivados, e dos biocombustíveis, tem a finalidade de garantir o abastecimento de combustíveis e defender os interesses dos consumidores;

- Agência Nacional de Saúde Suplementar é vinculada ao Ministério da Saúde, tem o propósito harmonizar o setor de plano de saúde no Brasil;

- Agência Nacional de Transportes Aquaviários é vinculada ao Ministério da Infraestrutura atua promovendo a adequada prestação de serviços de transporte aquaviário e de exploração da infraestrutura portuária e hidroviária, mantendo em harmonia os interesses público e privado;

- Agência Nacional de Transportes Terrestres é vinculada ao Ministério da Infraestrutura tem a incumbência de proporcionar aos usuários adequada infraestrutura e prestação de serviços de transporte terrestre, buscando sempre o aumento da satisfação dos serviços.

Sendo as agências reguladoras pessoas jurídicas de direito público que desempenham as funções de outorga, fiscalização, regulamentação, arbitramento do mercado e controle de bens, e serviços no setor em que regulam, são entidades de Estado e não de governo, ou seja, revestem-se de autonomia política, porém com missões públicas importantes regulando atividades relevantes socialmente. 


\subsection{METODOLOGIA UTILIZADA NO TRABALHO}

Nesta investigação utilizou-se o enfoque qualitativo e o estudo descritivo, foi uma pesquisa bibliográfica onde se estudou administração pública e seus princípios básicos, como também o papel das agências reguladoras, os instrumentos de coleta de dados do estudo foram: livros, revistas, sites da Internet, artigos e a legislação correlata. Este trabalho está classificado como pesquisa bibliográfica, pois o estudo foi realizado tendo como fonte os trabalhos já publicados, objetivando alcançar os objetivos e explicar o problema, segundo Cervo e Bervian.

A pesquisa bibliográfica procura explicar um problema a partir de referências teóricas publicadas em artigos, livros, dissertações e teses. Pode ser realizada independentemente ou como parte da pesquisa descritiva ou experimental. Em ambos os casos, busca-se conhecer e analisar as condições culturais ou científicas do passado sobre determinado assunto, tema ou problema (CERVO E BERVIAN, 2007, p. $60)$.

Aliado a pesquisa de dados utilizados pelos instrumentos de coletas mencionados, utilizou também informações do sistema da intranet e do site da Agência Nacional de Mineração, principalmente a regulamentação da Lei da Compensação Financeira pela Exploração de Recursos Minerais CFEM, no âmbito do setor de arrecadação.

\section{CONSIDERAÇÕES FINAIS}

Objetivando proporcionar um serviço público que atenda os anseios da população, a administração pública foi se modernizando e buscando procedimentos para alcançar eficiência, eficácia e efetividade, na nova gestão pública os resultados passam a ser uma forma de controle.

Com o fim de alguns monopólios estatais e consequente crescimento do setor privado em atividades de interesse social, com a finalidade de manutenção da qualidade da prestação desses serviços foram criadas as agências reguladoras, pessoas jurídicas de direito público, classificadas como autarquias de regime especial. 
As ações das agências reguladoras buscam a estabilidade do setor econômico e o bem-estar dos agentes envolvidos, procurando harmonizar e manter os direitos dos usuários, governo e das empresas executoras dos serviços ou bens.

A autonomia dessas autarquias permite que as decisões sejam pautadas em bases técnicas com o mínimo de interferência política, de modo que por meio da regulação do setor econômico, mantenha-se um mercado equilibrado com preço justo e oferta de bens e serviços de qualidade em prol do interesse público.

As agências reguladoras brasileiras exercem os seus papeis ou atribuições, através de fiscalização, outorga, regulamentação, arbitramento do mercado e, controle de bens e serviços no setor em que regulam.

\section{REFERENCIAS}

AMARAL, H. K. Desafios da Regulação no Brasil. Brasília: ENAP, 2009.

BITTENCOURT, M. V. C. Manual de Direito Administrativo, $2^{a}$ ed. Belo Horizonte: Fórum, 2007

CERVO, A. L., BERVIAN, P. A. e SILVA, R. Metodologia Científica, 6 ed. São Paulo: Pearson Prentice Hall, 2006.

CONSTITUIÇÃO DA REPÚBLICA FEDERATIVA DO BRASIL 1988: Disponível em <http://www.planalto.gov.br/ccivil_03/constituicao/constituicao.htm> Acesso em: 06 mar. 2013.

DENHARDT, R. B. Teorias da Administração Pública: Tradução da 6ª Ed. Norte Americana. (Trad. Francisco G. Heidemann). São Paulo: CENGAGE Learning, 2012.

DI PIETRO, M. S. Z. Direito Administrativo; 16aㅡ edição, São Paulo: Atlas, 2004.

Lei no 13.848/2019. Disponível em: <http://www.planalto.gov.br/ccivil_03/_ato20192022/2019/lei/L13848.htm> Acesso em: 17 out. 2020. 
MATIAS-PEREIRA, J. Curso de Administração Pública. São Paulo: Editora Atlas, 2008.

MEDAUAR, O. Direito Administrativo Moderno. 11르 Ed. Revista e atualizada. São Paulo: Editora Revista dos Tribunais, 2007.

MEIRELES, H. L. Direito Administrativo Brasileiro. 23ª Ed. São Paulo: Malheiros, 1998

PINHEIRO, R. P. A visão da Abar - Desafios da Regulação no Brasil. Brasília: ENAP, 2009.

ROQUE, A. Regulação do Mercado: Novas Tendências. Lisboa: Quid Juris? Sociedade Editora, 2004.

SITE DA ANA: Disponível em <https://www.gov.br/ana/pt-br> Acesso em: 17set. 2020

SITE DA ANAC: Disponível em <https://www.anac.gov.br/> Acesso em: 17set. 2020.

SITE DA ANATEL: Disponível em <https://www.anatel.gov.br/institucional/> Acesso em: 17set. 2020.

SITE DA ANCINE: Disponível em <https://www.ancine.gov.br/> Acesso em: 17set. 2020.

SITE DA ANEEL: Disponível em <https://www.aneel.gov.br/> Acesso em: 17set. 2020.

SITE DA ANM: Disponível em <https://www.gov.br/anm/pt-br> Acesso em: 01set. 2020

SITE DA ANP: Disponível em <http://www.anp.gov.br/> Acesso em: 17set. 2020.

SITE DA ANS: Disponível em <http://www.ans.gov.br/> Acesso em: 17set. 2020. 
SITE DA ANTAQ: Disponível em <http://portal.antaq.gov.br/> Acesso em: 17set. 2020.

SITE DA ANTT: Disponível em <https://www.gov.br/antt/pt-br> Acesso em: 17set. 2020.

SITE DA ANVISA: Disponível em <https://www.gov.br/anvisa/pt-br> Acesso em: 17set. 2020.

Enviado: Setembro, 2020.

Aprovado: Outubro, 2020. 